\title{
Overexpression of let-7a increases neurotoxicity in a PC12 cell model of Alzheimer's disease via regulating autophagy
}

\author{
HUIZI GU, LAN LI, CHEN CUI, ZIHUI ZHAO and GUIJUN SONG \\ First Department of Neurology, The Second Affiliated Hospital of \\ Dalian Medical University, Dalian, Liaoning 116023, P.R. China
}

Received October 19, 2016; Accepted June 16, 2017

DOI: $10.3892 /$ etm.2017.4977

\begin{abstract}
Increased deposition of $\beta$-amyloid $(\mathrm{A} \beta)$ protein is one of the typical characteristics of Alzheimer's disease (AD). Recent evidence has demonstrated that the microRNA let-7 family, which is highly expressed in the central nervous system, participates in the regulation of pathologic processes of $\mathrm{AD}$. In the present study, the effect of let-7a overexpression on A $\beta 1-40$-induced neurotoxicity was evaluated in PC12 and SK-N-SH cells. The results indicated that overexpression of let-7a enhanced the neurotoxicity induced by A $\beta 1-40$ in PC12 and SK-N-SH cells. In addition, the apoptosis induced by A $\beta 1-40$ in PC12 and SK-N-SH cells was increased by let-7a overexpression. Furthermore, A $\beta 1-40$ treatment increased the protein levels of microtubule-associated protein 1A/1B-light chain 3 (LC3) and beclin-1 and increased the LC3 II/I ratio. The mRNA expression levels of beclin-1, autophagy protein 5 (Atg-5) and Atg-7 were also increased by A $\beta 1-40$ treatment in PC12 cells. Let-7a overexpression further upregulated the above autophagy-related markers. Furthermore, the protein level of p62 was increased by A $\beta 1-40$ treatment, and this was further enhanced by let-7a overexpression. Finally, the present results demonstrated that the phosphoinositide-3-kinase (PI3K)/Akt/mammalian target of rapamycin (mTOR) signaling pathway was involved in the autophagy regulation by let-7a. In conclusion, the present study demonstrates that the neurotoxicity induced by $A \beta 1-40$ is augmented by let-7a overexpression via regulation of autophagy, and the PI3K/Akt/mTOR signaling pathway also serves a function in this process.
\end{abstract}

\section{Introduction}

Alzheimer's disease (AD) is the most prevalent disease of dementia, and is characterized as a chronic, progressive

Correspondence to: Dr Guijun Song, First Department of Neurology, The Second Affiliated Hospital of Dalian Medical University, 467 Zhongshan Road, Dalian, Liaoning 116023, P.R. China

E-mail: sgjd12016@163.com

Key words: let-7a, $\beta$-amyloid 1-40, Alzheimer's disease, autophagy, phosphoinositide-3-kinase/Akt/mammalian target of rapamycin neurodegenerative disorder (1). With the accelerated trend of population aging, the incidence of $\mathrm{AD}$ is rising. Based on epidemiological data, by 2050, the number of patients with AD in the USA will be more than three times higher than in 2010 (2), and a similar trend may be seen in China (3). The primary pathological changes of AD are neurofibrillary tangles, senile plaque deposits and neuronal cell death. $\beta$-amyloid $(A \beta)$ protein has been demonstrated to be a key component in senile plaques and tau protein hyperphosphorylation has been indicated to promote neurofibrillary tangles $(4,5)$.

In recent decades, the role of autophagy in $\mathrm{AD}$ development has attracted widespread attention. Increasing evidence has suggested that autophagy is a double-edged sword in AD development (6). Although a great deal of research has demonstrated that autophagy has a beneficial effect against AD (7-9), abnormalities of autophagy may also be a major risk factor for $\mathrm{AD}$ (10). $\mathrm{A} \beta 1-42$ or $\mathrm{A} \beta 1-40$, and their precursor amyloid precursor protein (APP), and $\beta$-cleaved carboxyl-terminal domain of APP have been demonstrated to be enriched in autophagic vacuoles (AVs) that were accumulated in abnormalities of autophagy (11). In addition, some scholars have suggested that significant accumulations of immature AVs indicate the failure of AV transport and maturation to lysosomes in AD $(12,13)$. The autophagic-lysosomal pathway dysfunction that results in AV accumulation and lysosomal proteolysis defects occurs in neurites throughout the AD brain (14). Cho et al (15) recently demonstrated that the vast accumulation of $\mathrm{AVs}$ was the cause for $\mathrm{A} \beta$ production in $\mathrm{AD}$. Therefore, defective autophagy contributes to the course of AD.

The abnormal expression of microRNA (miRNA) is reported to be closely associated with the pathogenesis of AD. The let-7 miRNA family was first identified in Caenorhabditis elegans and is highly conserved in multiple species (16). Let-7 is known as a classical development regulator, which participates in the regulation of various physiological and pathological events such as cell proliferation, differentiation, apoptosis, immune response, tumorigenesis and metastasis (17). Dubinsky et al (18) recently reported that let-7 miRNA promoted autophagy in primary cortical neurons in vitro and in the brain in vivo. Furthermore, the expression of let-7a, let-7b and let-7e were upregulated in the progression of AD in a rabbit model (19). However, the expression of let-7d and let- $7 \mathrm{~g}$ was found to be downregulated in plasma samples 
of patients with AD (20). At present, the effect of let-7a on autophagy in the process of $\mathrm{AD}$ has yet to be determined.

In the present study, $A \beta 1-40$-treated adrenal pheochromocytoma PC12 and human neuroblastoma SK-N-SH cell lines were used to establish AD models in vitro. The effect of let-7a on A $\beta 1-40$-induced neurotoxicity was investigated. It was identified that overexpression of let-7a aggravated the A $31-40$-induced injury in PC12 and SK-N-SH cells by regulating autophagy.

\section{Materials and methods}

Cell culture and treatment. PC12 and SK-N-SH cells were purchased from the Cell Bank of Type Culture Collection of Chinese Academy of Sciences, Shanghai, China. PC12 cells were maintained in RPMI-1640 (31800-014; Gibco; Thermo Fisher Scientific, Inc., Waltham, MA, USA) supplemented with $10 \%$ fetal bovine serum (FBS; SH30084.03; Hyclone; GE Healthcare Life Sciences; Logan, UT, USA) 100 U/ml penicillin and $100 \mathrm{U} / \mathrm{ml}$ streptomycin. SK-N-SH cells were maintained in minimum essential medium (MEM, 41500034, Gibco; Thermo Fisher Scientific, Inc.) supplemented with $10 \%$ FBS, $100 \mathrm{U} / \mathrm{ml}$ penicillin and $100 \mathrm{U} / \mathrm{ml}$ streptomycin. The two cell lines were cultured at $37^{\circ} \mathrm{C}$ under a humidified atmosphere of $5 \% \mathrm{CO}_{2}$. A $\beta 1-40$ (GL Biochem, Ltd., Shanghai, China) was dissolved in sterile PBS and incubated for 5 days at $37^{\circ} \mathrm{C}$ to induce aggregation prior to treatment. $4 \times 10^{3}$ cells/well $\mathrm{PC} 12$ and SK-N-SH cells were seeded in 6-well plates and then treated with $500 \mathrm{nM} \mathrm{A} \beta 1-40$ for 7 days at $37^{\circ} \mathrm{C}$ to establish the AD model.

Transient transfection. The let-7a mimic and scrambled negative control miRNA (miR-NC) were obtained from Shanghai GenePharma Co., Ltd. (Shanghai, China). The sequences were as follows: let-7a mimic, 5'-UGAGGUAGUAGGUUGUAU AGUU-3'; miR-NC 5'-UUCUCCGAACGUGUCACGUTT-3'. A $\beta 1-40$-treated PC12 and SK-N-SH cells were transfected with 100 pmol let-7a mimic or miR-NC using Lipofectamine 2000 (Invitrogen; Thermo Fisher Scientific, Inc.), following the manufacturer's protocol. The cells were divided into four groups: Control, $\mathrm{A} \beta 1-40, \mathrm{~A} \beta 1-40+$ let-7a mimic and $\mathrm{A} \beta 1-40+\mathrm{miR}$ NC. Cells were collected for various assays at 24 or $48 \mathrm{~h}$ after the transfection.

RNA extraction and reverse transcription-quantitative polymerase chain reaction ( $R T-q P C R)$. At $24 \mathrm{~h}$ after the transfection, total RNA from PC12 cells and SK-N-SH cells was extracted using TRIzol reagent (Invitrogen; Thermo Fisher Scientific, Inc.) following the manufacturer's protocol. For mRNA analysis, cDNA was synthesized using a PrimeScript ${ }^{\mathrm{TM}}$ 1st strand cDNA Synthesis Kit (Takara Bio, Inc., Otsu, Japan) followed according to the manufacturer's protocol. For miRNA analysis, cDNA was synthesized using an miScript Reverse Transcription kit (Qiagen GmbH, Hilden, Germany) followed according to the manufacturer's protocol. Then, qPCR was performed using a SYBR Premix Ex Taq II kit (Takara Bio, Inc.) in a 7500 Real-Time PCR system (Applied Biosystems; Thermo Fisher Scientific, Inc.). The thermocycling conditions consisted of denaturation at $95^{\circ} \mathrm{C}$ for $10 \mathrm{~min}, 95^{\circ} \mathrm{C}$ for $10 \mathrm{sec}$, annealing at $60^{\circ} \mathrm{C}$ for $20 \mathrm{sec}$, extension at $72^{\circ} \mathrm{C}$ for $30 \mathrm{sec}$ for
40 cycles. The primer sequences used are shown in Table I. In three repeated experiments, the mRNA and miRNA expression levels were normalized to internal controls $\beta$-actin and U6 using the $2^{-\Delta \Delta \mathrm{Cq}}$ method (21), respectively.

MTT assay. An MTT assay was performed to evaluate cell viability at $48 \mathrm{~h}$ after the transfection. Briefly, $3 \times 10^{3} \mathrm{PC} 12$ and SK-N-SH cells/well were seeded in 96-well plates and exposed to the aforementioned treatments. Subsequently, $20 \mu 1 \mathrm{MTT}$ (Sigma-Aldrich; Merck KGaA, Darmstadt, Germany) at a concentration of $5 \mathrm{mg} / \mathrm{ml}$ was added into each well. Following incubation for $4 \mathrm{~h}$ at $37^{\circ} \mathrm{C}$, the medium was discarded and $200 \mu \mathrm{l}$ DMSO was added into each well. The formazan crystalline product was dissolved and optical density was measured at $490 \mathrm{~nm}$ using a microplate reader.

Hoechst 33342 staining. At $48 \mathrm{~h}$ after the transfection, Hoechst 33342 staining was performed to evaluate the morphological changes of apoptotic nuclei. $2 \times 10^{6} \mathrm{PC} 12$ and SK-N-SH cells/well were seeded into 6 -well plates and subjected to the aforementioned treatments. The cells were fixed with $4 \%$ paraformaldehyde for $20 \mathrm{~min}$ at room temperature. Subsequently, the cells were washed with PBS and incubated with $10 \mu \mathrm{g} / \mathrm{ml}$ Hoechst 33342 for $5 \mathrm{~min}$ at $37^{\circ} \mathrm{C}$. Following washing with PBS three times for 3 min each, the cells were observed under a fluorescence microscope at a magnification of $x 400$. The apoptotic nuclei appeared condensed or fragmented compared with normal nuclei.

Flow cytometry for cell apoptosis analysis. At $48 \mathrm{~h}$ after the transfection, the percentage of apoptosis in PC12 cells was quantified using the Annexin V-Fluorescein Isothiocyanate (FITC)/Propidium Iodide (PI) Apoptosis Detection kit (KGA106; KeyGen Biotech Co., Ltd., Nanjing, China), according to the manufacturer's protocol. Briefly, $2 \times 10^{6}$ cells from different groups were washed with PBS, stained with Annexin V-FITC and PI for $15 \mathrm{~min}$ in the dark at room temperature. Then samples (10,000 cells/sample) were analyzed using a flow cytometer (BD Accuri C6; BD Biosciences, San Jose, CA, USA).

Western blot analysis. At $48 \mathrm{~h}$ after the transfection, western blot assay was performed. The following primary antibodies were used: Anti-phosphoinositide 3-kinase (PI3K) (1:500; WL02240; Wanleibio, Co., Ltd., Shenyang, China), anti-Akt (1:500; WL0003; Wanleibio, Co., Ltd.), anti-phosphorylated (p)-Akt (1:500; WLP001; Wanleibio, Co., Ltd.), anti-mammalian target of rapamycin (mTOR; 1:200; sc-101738; Santa Cruz Biotechnology, Inc., Dallas, TX, USA), anti-p-mTOR (sc-8319; 1:200; Santa Cruz Biotechnology, Inc.), anti-microtubule-associated protein 1A/1B-light chain 3 (LC3; 1:500; WL01506; Wanleibio, Co., Ltd.), anti-beclin-1 (1:500; WL02237; Wanleibio, Co., Ltd.), anti-p62 (1:500; WL02385; Wanleibio, Co., Ltd.), anti- $\beta$-actin (1:500; WL01845; Wanleibio, Co., Ltd.). Briefly, cells were lysed with RIPA lysis buffer (Beyotime Institute of Biotechnology, Haimen, China). Protein concentration was determined using the BCA method. Proteins from each sample $(20 \mu \mathrm{g})$ were separated by 8,10 or $13 \%$ SDS-PAGE and transferred to polyvinylidene fluoride membranes. The 
Table I. Oligonucleotide primer sets for quantitative polymerase chain reaction.

\begin{tabular}{llc}
\hline Name & \multicolumn{1}{c}{ Sequence (5'-3') } & Length (bp) \\
\hline Beclin-1 & F: CAGCAGTTCAAAGAAGAGGTG & 21 \\
& R: GAGGACACCCAAGCAAGAC & 19 \\
Atg-5 & F: AGTGGAGGCAACAGAACCC & 19 \\
& R: TCCGACCACCGTCACCTTA & 21 \\
Atg-7 & F: GGGCTATTACTACAATGGTGAC & 22 \\
& R: TCTCATTGGCTGACTGCTC & 19 \\
Let-7a & F: GCGACGATGAGGTAGTAGGTTGT & 23 \\
& R: GTGCAGGGTCCGAGGTATTC & 20 \\
\$-actin & F: GGAGATTACTGCCCTGGCTCCTAGC & 25 \\
U6 & R: GGCCGGACTCATCGTACTCCTGCTT & 25 \\
& F: CTCGCTTCGGCAGCACA & 17 \\
\hline
\end{tabular}

F, forward; R, reverse; Atg, autophagy protein.

membranes were blocked with 5\% dried skimmed milk for $1 \mathrm{~h}$ at room temperature and incubated with primary antibodies at $4^{\circ} \mathrm{C}$ overnight. Subsequently, IgG conjugated goat anti-rabbit (1:5,000; WLA023; Wanleibio Co., Ltd.) or IgG conjugated goat anti-mouse (1:5,000; WLA024; Wanleibio Co., Ltd.) secondary antibodies were added for $30 \mathrm{~min}$ at room temperature. Blots were developed using enhanced chemiluminescence detection reagent (Beyotime Institute of Biotechnology). Scanning densitometry using a Gel-Pro Analyzer 4 software (Media Cybernetics, Inc., Rockville, MD, USA) was used to assess the level of each target protein relative to $\beta$-actin in three repeated experiments.

Immunofluorescence staining. Briefly, at $48 \mathrm{~h}$ after the transfection, $2 \times 10^{6}$ PC12 cells from different treatment groups were plated to slides and fixed with $4 \%$ paraformaldehyde for $15 \mathrm{~min}$ at room temperature. After washing with PBS three times for $5 \mathrm{~min}$ each, the cells were permeabilized with $0.1 \%$ Triton $\mathrm{X}-100$ for $30 \mathrm{~min}$ at room temperature, followed by blocking with $10 \%$ normal goat serum (Beijing Solarbio Science and Technology Co., Ltd., Beijing, China) for $15 \mathrm{~min}$ at room temperature. Cells were subsequently incubated with primary antibody LC3 (WL01506; Wanleibio, Co., Ltd.) at a 1:200 dilution at $4^{\circ} \mathrm{C}$ overnight. After washing with PBS three times, the cells were incubated with $\mathrm{Cy} 3$-conjugated secondary antibody (dilution, 1:200; A0516; Beyotime Institute of Biotechnology) for $30 \mathrm{~min}$. The nuclei of cells were stained with DAPI for $5 \mathrm{~min}$ at room temperature. Slides were viewed by immunofluorescence microscopy (BX53; Olympus Corp., Tokyo, Japan) at x400 magnification.

Inhibition of autophagy in PC12 cells. To inhibit autophagy, PC12 cells $\left(2 \times 10^{6}\right.$ cells/well $)$ were incubated with the autophagy inhibitor 3-methyladenine (3-MA; $1 \mathrm{mM}$; Sigma-Aldrich; Merck KGaA) at $37^{\circ} \mathrm{C}$ for $1 \mathrm{~h}$ prior to transfection with let-7a mimic. The cells were divided into five groups: Control, $\mathrm{A} \beta 1-40, \mathrm{~A} \beta 1-40+$ let-7a mimic, $\mathrm{A} \beta 1-40+$ miR-NC and $\mathrm{A} \beta 1-40+$ let-7a mimic + 3-MA.
Activation of the PI3K/Akt/mTOR pathway in PC12 cells. To induce activation of the PI3K/Akt/mTOR pathway, PC12 cells with different treatments were treated with $100 \mathrm{ng} / \mathrm{ml}$ insulin-like growth factor 1 (IGF-1; Bachem AG, Bubendorf, Switzerland prior to transfection for $48 \mathrm{~h}$ at $37^{\circ} \mathrm{C}$. The cells were divided into five groups: Control, $\mathrm{A} \beta 1-40, \mathrm{~A} \beta 1-40+$ let-7a mimic, $\mathrm{A} \beta 1-40+$ miR-NC and A $\beta 1-40+$ let-7a mimic + IGF-1.

Statistical analysis. Data are expressed as the mean \pm standard deviation. Differences among groups were evaluated by one-way analysis of variance followed by Bonferroni's multiple comparison test using GraphPad Prism 5 software (GraphPad Software, Inc., La Jolla, CA, USA). P<0.05 was considered to indicate a statistically significant difference.

\section{Results}

Expression of let-7a in PC12 and SK-N-SH cells. To investigate the role of let-7a in A $\beta 1-40$-treated PC12 and SK-N-SH cells, the let-7a mimic was transfected into PC12 and SK-N-SH cells. The levels of let-7a in PC12 and SK-N-SH cells were subsequently detected by RT-qPCR. As shown in Fig. 1, in both cell types, the level of let-7a in the A $\beta 1-40+$ let-7a mimic group was significantly higher compared with the $A \beta 1-40$ group $(\mathrm{P}<0.001)$.

Effect of let-7a on cell viability in A $\beta 1-40$-treated PC12 and $S K-N-S H$ cells. After transfection for $24 \mathrm{~h}$, cell viability was assessed by MTT assay. As shown in Fig. 2, A $\beta 1-40$ treatment resulted in a significant decrease in cell viability compared with the control group in both cell lines $(\mathrm{P}<0.001)$. Furthermore, overexpression of let-7a significantly decreased the cell viability in PC12 and SK-N-SH cells compared with the $\mathrm{A} \beta 1-40$ group $(\mathrm{P}<0.05$ and $\mathrm{P}<0.01$, respectively).

Effect of let-7a on apoptosis in A 31 -40-treated PC12 and $S K-N-S H$ cells. The effect of let-7a on A $\beta 1-40$-induced apoptosis in PC12 and SK-N-SH cells was determined by Annexin V-FITC/PI staining. As shown in Fig. 3A and B, 

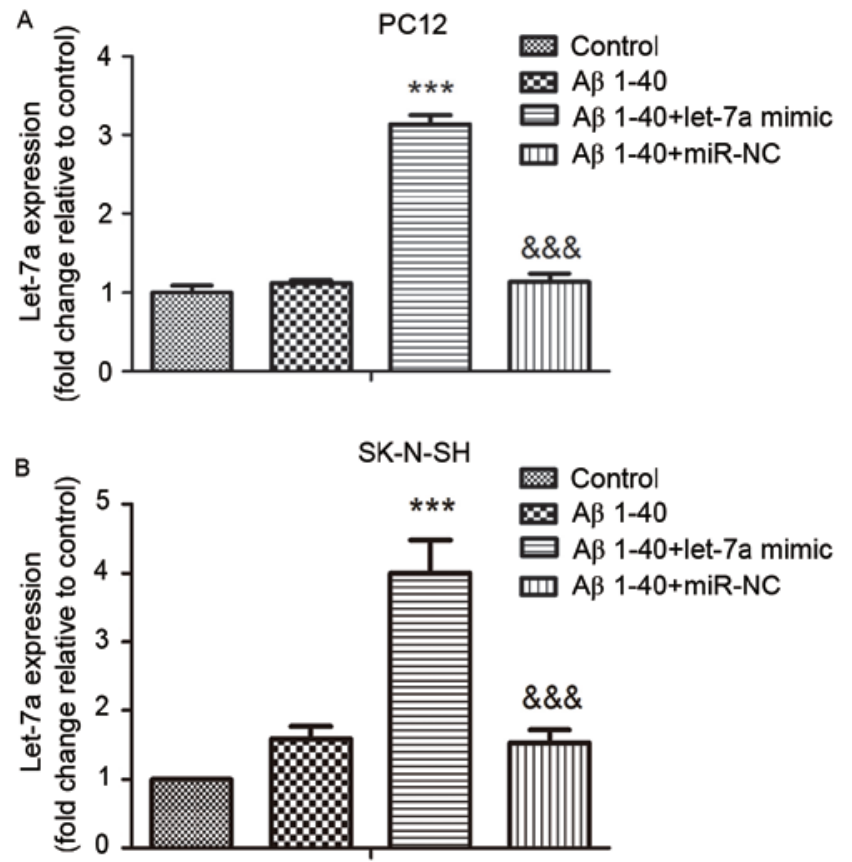

Figure 1. Effect of let-7a mimic transfection on let-7a expression in A $31-40$-treated (A) PC12 and (B) SK-N-SH cells. The levels of let-7a were assessed by reverse transcription-quantitative polymerase chain reaction. Data are presented as the mean \pm standard deviation $(\mathrm{n}=3) .{ }^{* * *} \mathrm{P}<0.001$ vs. $\mathrm{A} \beta 1-40$ group; ${ }^{\& \& \&} \mathrm{P}<0.001$ vs. $\mathrm{A} \beta 1-40+$ let-7a mimic group. $\mathrm{A} \beta$, $\beta$-amyloid; miR-NC, negative control microRNA.
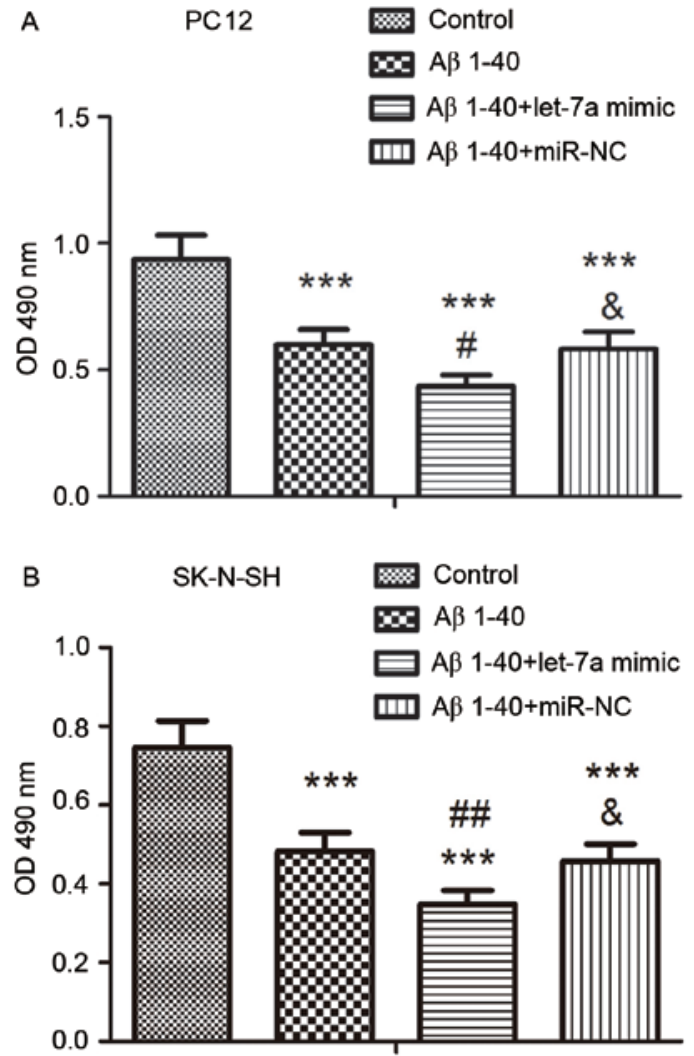

Figure 2. Effect of let-7a overexpression on cell viability in A $\beta 1-40$-treated (A) PC12 and (B) SK-N-SH cells. Cell viability was determined by MTT assay. Data are presented as the mean \pm standard deviation $(n=5)$. ${ }^{* * * *} \mathrm{P}<0.001$ vs. control group; ${ }^{\#} \mathrm{P}<0.05,{ }^{\# \#} \mathrm{P}<0.01$ vs. $\mathrm{A} \beta 1-40$ group; ${ }^{\&} \mathrm{P}<0.05$ vs. $\mathrm{A} \beta 1-40+$ let-7a mimic group. $\mathrm{A} \beta, \beta$-amyloid; miR-NC, negative control microRNA; OD, optical density. after transfection for $24 \mathrm{~h}$ the percentage of apoptosis induced by A $\beta 1-40$ was significantly increased by overexpression of let-7a in the two cell lines, compared with controls $(\mathrm{P}<0.001)$. Furthermore, the morphological changes of apoptotic nuclei were assessed by Hoechst 33342 staining and are presented in Fig. 3C. There were more condensed or fragmented apoptotic nuclei in the A $\beta 1-40$ group in PC12 and SK-N-SH cells compared with the control, and let-7a overexpression markedly increased this phenomenon compared with the $\mathrm{A} \beta 1-40$ group.

Effect of let-7a on autophagy in Aß1-40-treated PC12 and $S K-N$-SH cells. To elucidate the role of let-7a in the regulation of autophagy, the expression of LC3 among different groups of $\mathrm{PC} 12$ cells was determined by immunofluorescence staining. As shown in Fig. 4A, A $\beta 1-40$ induced a marked increase in LC3 expression compared with control, and let-7a overexpression further increased LC3 expression induced by A $\beta 1-40$ treatment. Furthermore, the levels of LC3 I, LC3 II, beclin-1 and p62 were assessed by western blotting (Fig. 4B-E). The ratio of LC3 II/I and the levels of beclin-1 and p62 were significantly upregulated by $\mathrm{A} \beta 1-40$ treatment in $\mathrm{PC} 12$ cells compared with the control (all $\mathrm{P}<0.05$ ). These results were further increased by let-7a overexpression in $\mathrm{PC} 12$ cells $(\mathrm{P}<0.05, \mathrm{P}<0.05$ and $\mathrm{P}<0.001$, respectively). Likewise, in SK-N-SH cells the ratio of LC3 II/I induced by A $\beta 1-40$ was significantly upregulated by let-7a overexpression (Fig. 4F and G; $\mathrm{P}<0.01$ ).

As shown in Fig. 5A-C, the mRNA expression levels of beclin-1, Atg-5 and Atg-7 were determined by RT-qPCR. The results indicated that the expression levels of beclin-1, Atg-5 and Atg-7 in A $31-40$-treated PC12 cells were increased significantly compared with the control group (all $\mathrm{P}<0.001$ ). Overexpression of let-7a led to higher levels of beclin-1, Atg-5 and Atg-7 expression compared with the A $\beta 1-40$ group $(\mathrm{P}<0.001$ for all). Furthermore, treatment with autophagy inhibitor 3-MA was able to restrain the morphological changes of apoptotic nuclei aggravated by let-7a overexpression in the context of A $\beta 1-40$-treated PC12 cells (Fig. 5D). The apoptosis rate increased by let-7a overexpression was also significantly inhibited by 3-MA in A $31-40$-treated PC12 cells (Fig. 5E; $\mathrm{P}<0.001)$. The results indicated that let-7a overexpression aggravated $A \beta 1-40$-induced apoptosis, at least in part, via activating autophagy.

Effect of let-7a on the PI3K/Akt/mTOR signaling pathway. As the activation of PI3K/AKT/mTOR pathway has been reported to block autophagy (22), the role of let-7a in the regulation of $\mathrm{PI} 3 \mathrm{~K} / \mathrm{AKT} / \mathrm{mTOR}$ pathway was investigated in the current study in PC12 cells. The results of western blot analysis (Fig. 6) indicated significant decreases in the levels of PI3K, p-Akt and p-mTOR in the A $\beta 1-40$ treatment group compared with the control group (all $\mathrm{P}<0.01$ ), which were further decreased by let-7a overexpression (all $\mathrm{P}<0.05$ ). Furthermore, the PI3K/AKT pathway was activated by treatment with IGF-1 and the changes in apoptosis and autophagy were evaluated in PC12 cells. As shown in Fig. 7A-C, the levels of PI3K and p-AKT were significantly upregulated by IGF-1 compared with the let-7a overexpression group $(\mathrm{P}<0.001$ and $\mathrm{P}<0.05$, respectively). The increased apoptosis rate induced by let-7a overexpression was restrained by IGF-1 in A $31-40$-treated PC12 cells $(\mathrm{P}<0.001$; Fig. 7D and $\mathrm{E})$. The morphological 

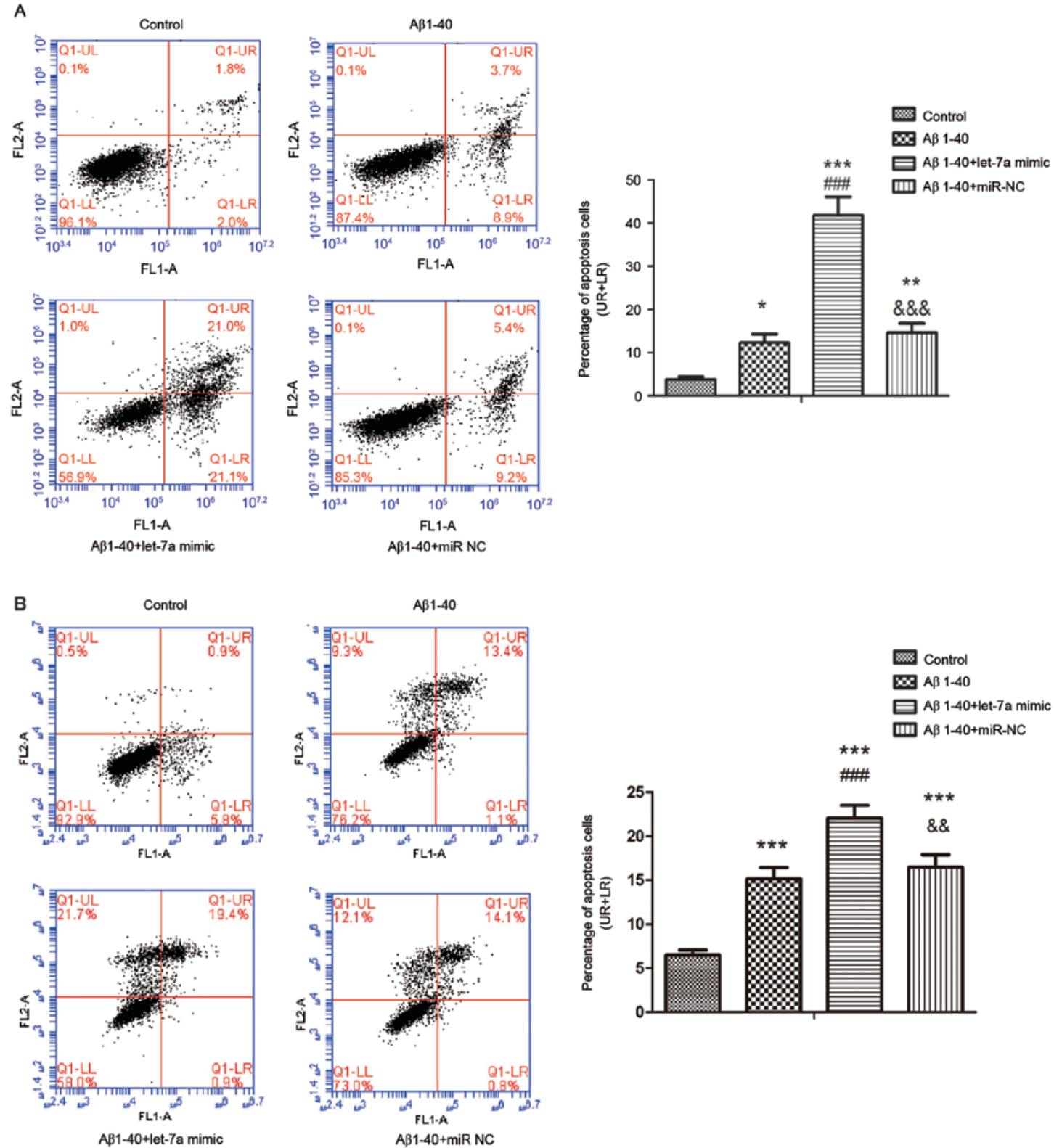

C

Control

AB1-40
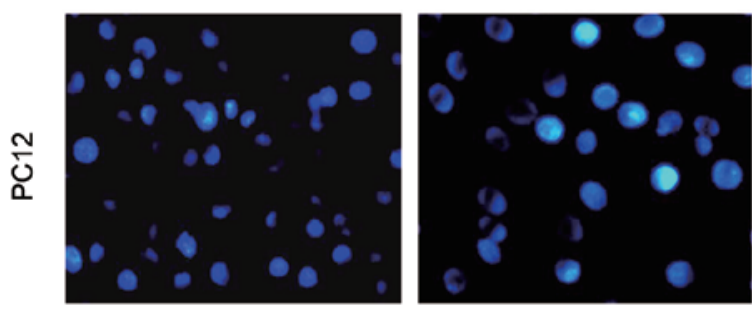

AB1-40+let-7a mimic

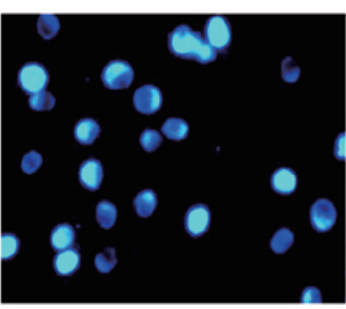

AB1-40+miR NC
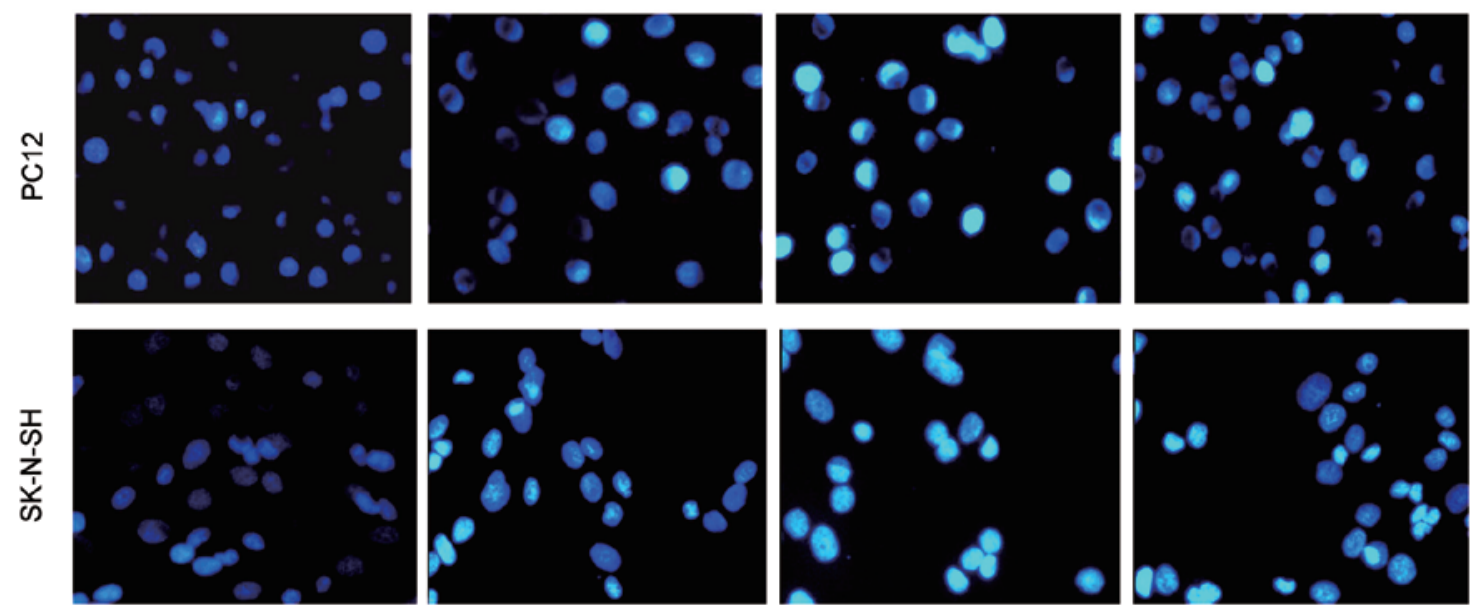

Figure 3. Overexpression of let-7a promoted the apoptosis of A $\beta 1-40$-treated PC12 and SK-N-SH cells. Annexin-V/PI staining by flow cytometry was used to determine the apoptosis rate of (A) PC12 and (B) SK-N-SH cells. The percentages of apoptotic cells in the UR and LR quadrants are presented in the column charts. (C) Morphological changes of the nuclei in PC12 and SK-N-SH cells were assessed by Hoechst 33342 staining and representative images are shown (magnification, $\mathrm{x} 400$ ). Data are presented as the mean \pm standard deviation $(\mathrm{n}=3) .{ }^{*} \mathrm{P}<0.05,{ }^{* * *} \mathrm{P}<0.01,{ }^{* * * *} \mathrm{P}<0.001$ vs. control group; ${ }^{\# \# \#} \mathrm{P}<0.001$ vs. $\mathrm{A} \beta 1-40$ group; ${ }_{\& \&} \mathrm{P}<0.01,{ }^{\& \&} \mathrm{P}<0.001$ vs. A $\beta 1-40$ + let-7a mimic group. UR, upper right; LR, lower right; A $\beta, \beta$-amyloid; miR-NC, negative control microRNA. 
A
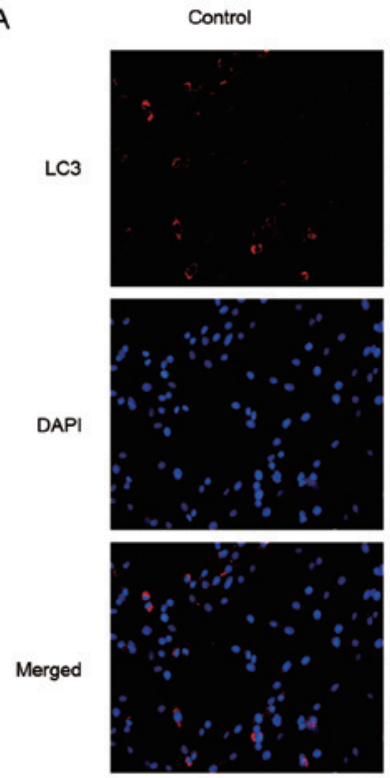

B

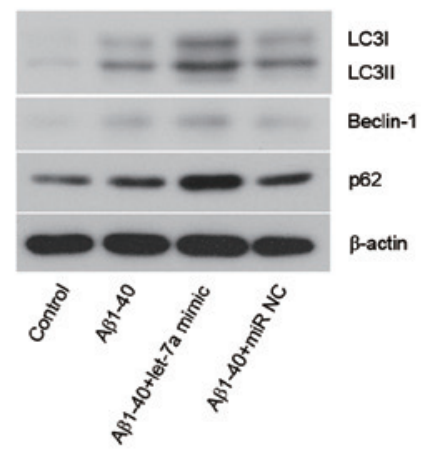

D

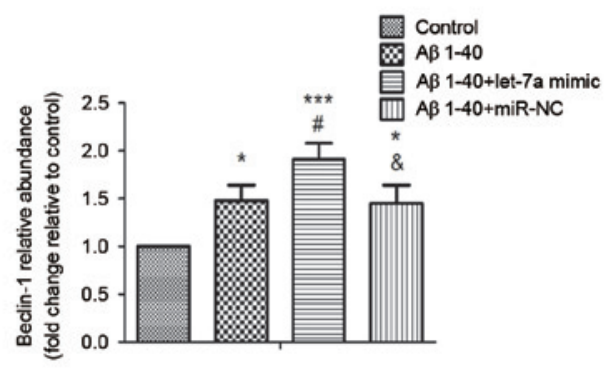

F

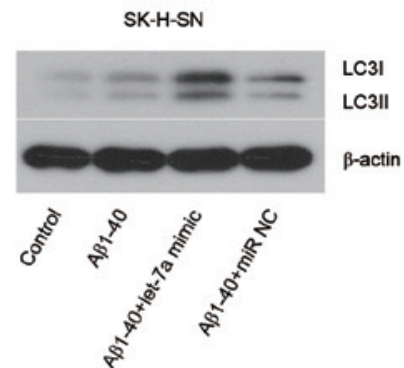

A $1-40$
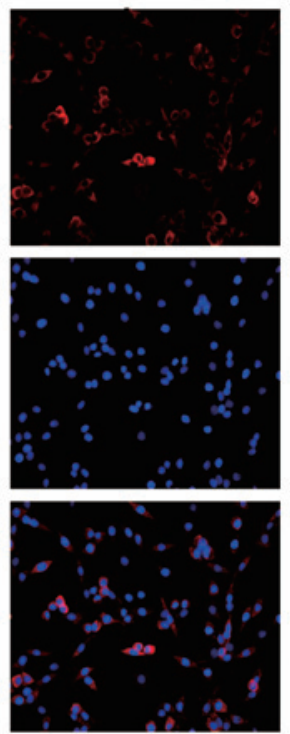

AB1-40+let-7a mimic
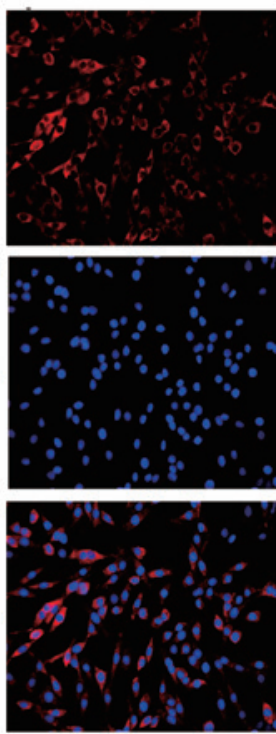

PC12
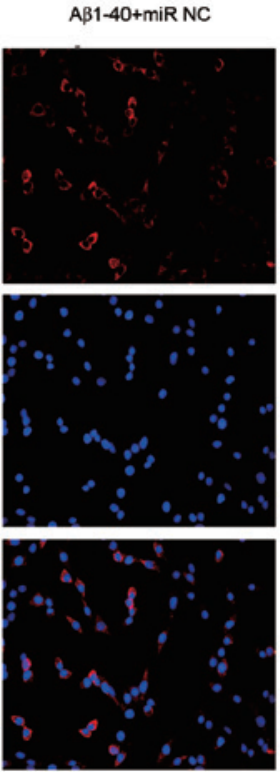

C

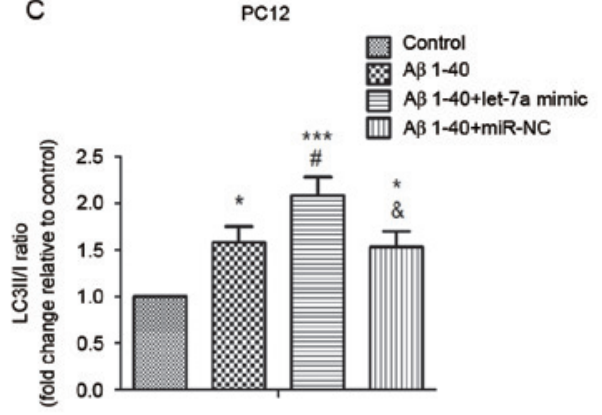

E

PC12

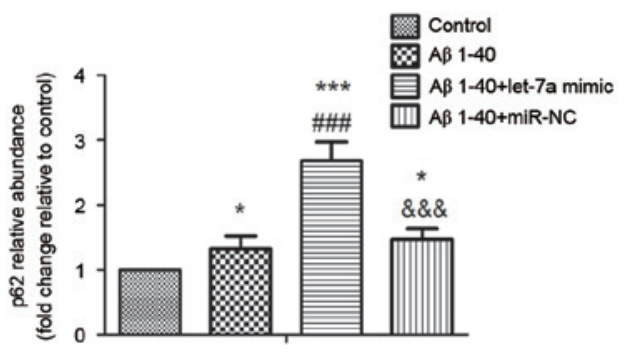

G

SK-H-SN Control

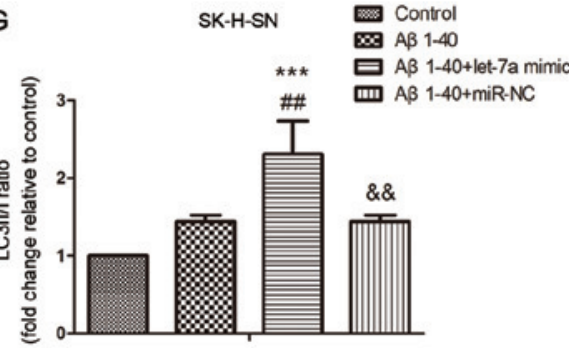

Figure 4. Effect of let-7a overexpression on LC3, beclin-1 and p62 protein expression in A $31-40$-treated PC12 and SK-H-SN cells. (A) Expression of LC3 in PC12 cells was evaluated by immunofluorescence staining. (B) Protein levels of LC3 I, LC3 II, beclin-1 and p62 in PC12 cells were assessed by western blot analysis. $\beta$-actin was used as a loading control. (C-E) Densitometric analysis of each protein band. (F) Protein levels of LC3 I and LC3 II in SK-H-SN cells were assessed by western blot analysis. $\beta$-actin was used as a loading control. (G) Densitometric analysis of each protein band. Data are presented as the mean \pm standard deviation $(\mathrm{n}=3) .{ }^{*} \mathrm{P}<0.05,{ }^{* * *} \mathrm{P}<0.001$ vs. control group; ${ }^{\#} \mathrm{P}<0.05,{ }^{\# \#} \mathrm{P}<0.01,{ }^{\# \# \#} \mathrm{P}<0.001$ vs. A $\beta 1-40$ group; ${ }^{\&} \mathrm{P}<0.05,{ }^{\&} \& \mathrm{P}<0.01,{ }^{\& \& \&} \mathrm{P}<0.001$ vs. A $\beta 1-40+$ let-7a mimic group. A $\beta$, $\beta$-amyloid; miR-NC, negative control microRNA; LC3, microtubule-associated protein $1 \mathrm{~A} / 1 \mathrm{~B}-$ light chain 3 . 

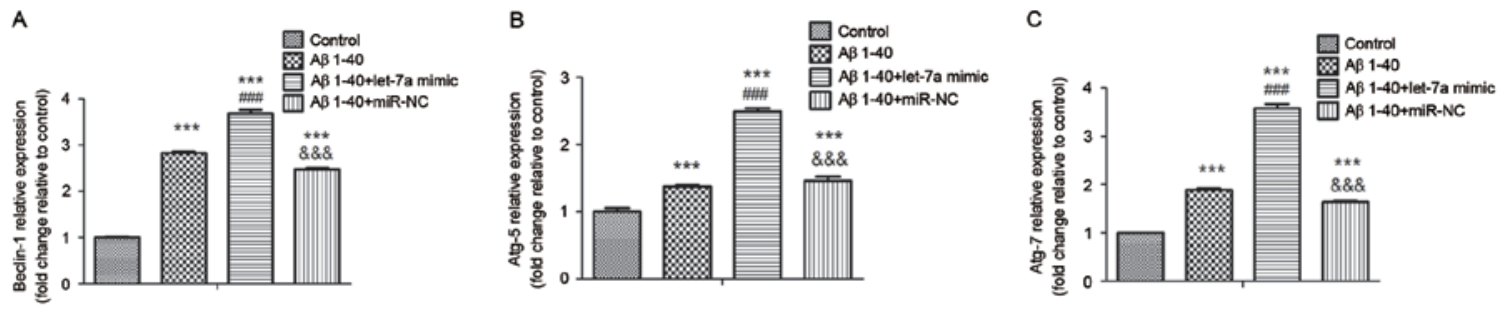

D
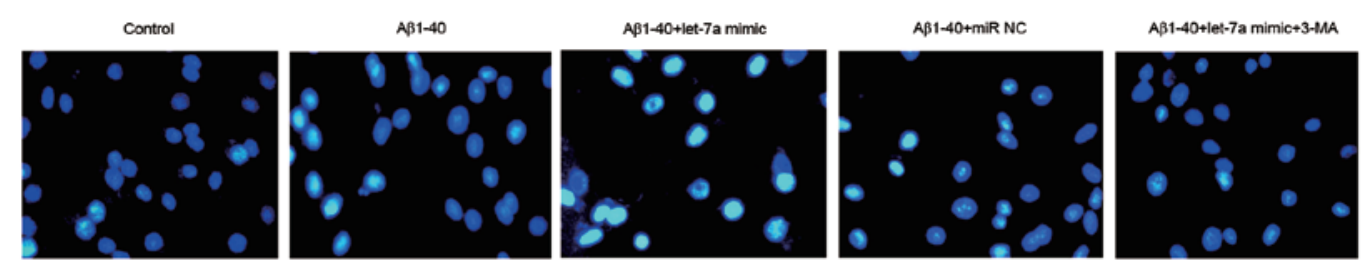

E
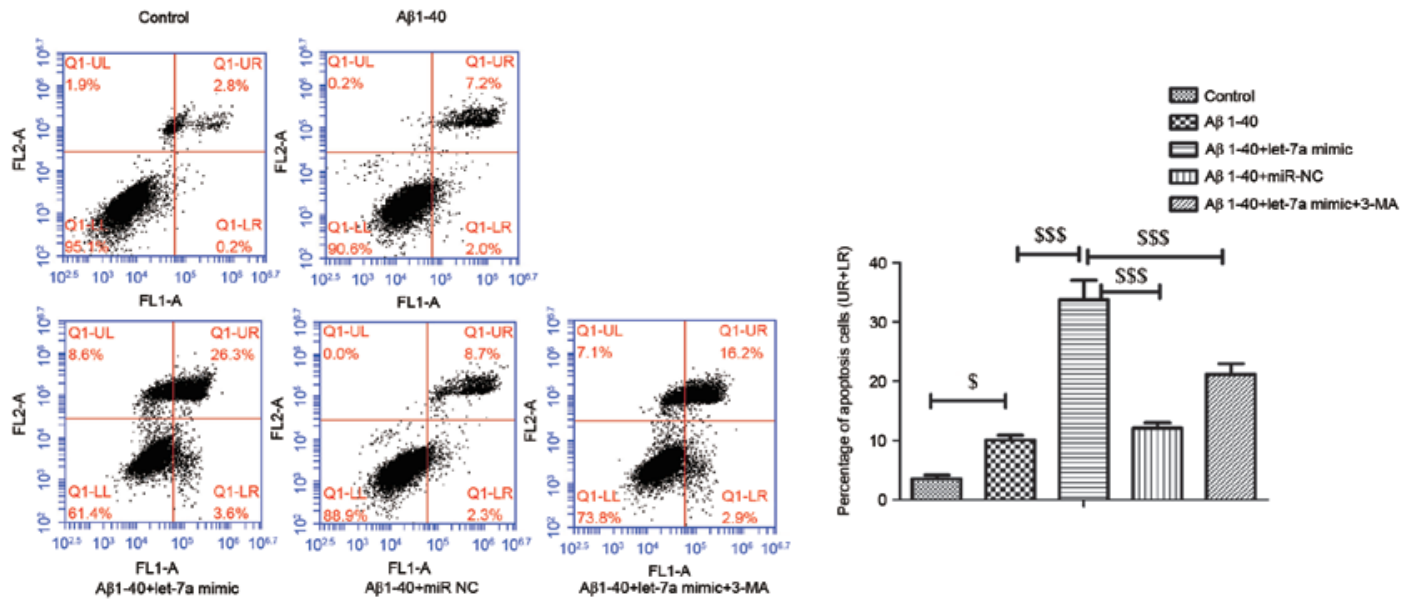

Figure 5. Effect of let-7a overexpression on beclin-1, Atg-5 and Atg-7 mRNA expression in A $\beta 1-40$-treated PC12 cells. (A-C) mRNA expression of beclin-1, Atg-5 and Atg-7 in PC12 cells was assessed by reverse transcription-quantitative polymerase chain reaction. (D) Representative pictures of the morphological changes of nuclei in PC12 cells stained by Hoechst 33342 (magnification, x400). (E) Annexin-V/PI staining by flow cytometry was used to determine the apoptosis rate of PC12 cells. The percentages of apoptotic cells in the UR \& LR quadrants are presented in the column charts. Data are presented as the mean \pm standard deviation $(\mathrm{n}=3) .{ }^{* * *} \mathrm{P}<0.001$ vs. control group; ${ }^{\# \# \#} \mathrm{P}<0.001$ vs. A $\beta 1-40$ group; ${ }^{\& \& \&} \mathrm{P}<0.001$ vs. A $\beta 1-40+1$ let-7a mimic group; ${ }^{\$} \mathrm{P}<0.05,{ }^{\$ \$ \$} \mathrm{P}<0.001$ as indicated. UR, upper right; LR, lower right; A $\beta$, $\beta$-amyloid; miR-NC, negative control microRNA; Atg, autophagy protein; 3-MA, 3-methyladenine.

changes of apoptotic nuclei aggravated by let-7a overexpression were alleviated by IGF-1 in A $\beta 1-40$-treated PC12 cells (Fig. 7F). Furthermore, the ratio of LC3 II/I promoted by let-7a overexpression was significantly reduced by IGF-1 in A 31 -40-treated PC12 cells $(\mathrm{P}<0.01$; Fig. $7 \mathrm{G}$ and $\mathrm{H})$. These results suggested that inhibition of the PI3K/Akt/mTOR signaling pathway is involved in the regulation of autophagy by let-7a overexpression, which strengthens A $\beta 1-40$-induced neurotoxicity.

\section{Discussion}

The current study provides new insight into the effect of let-7a on autophagy in AD models in vitro. A $\beta 1-40$-induced PC12 and SK-N-SH cells were used as the in vitro AD models in the present study, which have been adopted as models of neurotoxicity in previous research $(23,24)$. In the present study, it was demonstrated that overexpression of let-7a promoted impaired autophagy and exacerbated neurotoxicity in A $\beta 1-40$-induced PC12 and SK-N-SH cells.

The excessive accumulation of $\mathrm{A} \beta$ may result in senile plaque formation, which is considered to be the characteristic pathology change of AD (25). Increasing evidence has suggested that the abnormal accumulation of $A \beta$ may induce marked cytotoxicity in neurons and is a key pathogenic factor of $\mathrm{AD}$ (26-28). In the present study, an $\mathrm{A} \beta$ peptide, $\mathrm{A} \beta 1-40$, was used to investigate the mechanism of $A \beta$ neurotoxicity. According to the results, A $\beta 1-40$-treated cells exhibited a notable decrease in cell viability and a higher apoptosis rate compared with the control group, which was consistent with previous studies $(23,24)$. Furthermore, overexpression of let-7a was able to further decrease cell viability and enhance the level of apoptosis compared with the A $\beta 1-40$ treatment group. The above results suggested that overexpression of let- $7 \mathrm{a}$ enhanced A $\beta 1-40$-induced neurotoxicity in vitro.

The role of autophagy in AD is complicated and may be regarded as a double-edged sword. On the one hand, autophagy has been reported to result in $\mathrm{A} \beta$ production, and inhibition of autophagy could reduce the accumulation of $A \beta$ (29). For example, galanthamine, the drug typically used for treating $\mathrm{AD}$, has been identified to have the potential to inhibit autophagy (30). Conversely, the activation of autophagy was indicated to improve cognitive function and decrease senile plaque production in a mouse model of $\mathrm{AD}$ (31). Currently, the 
A

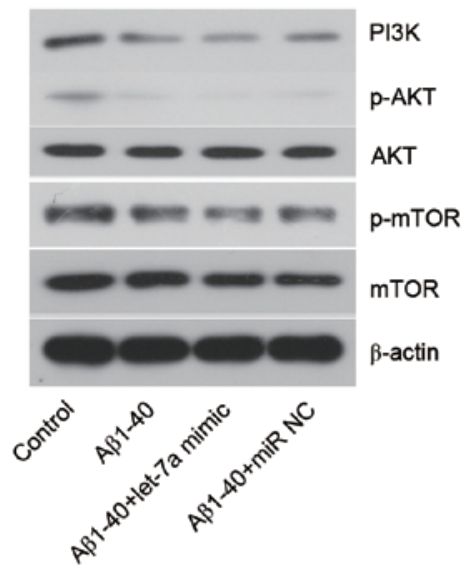

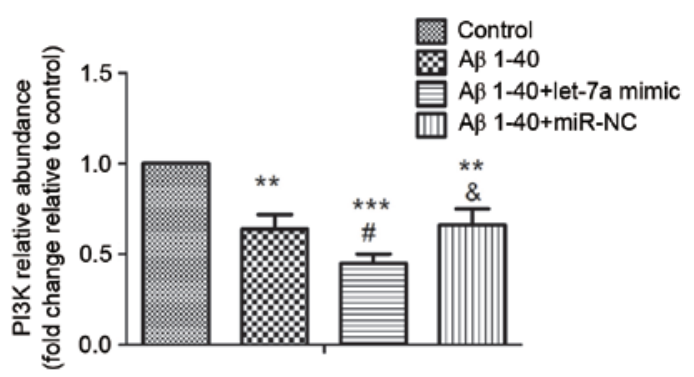

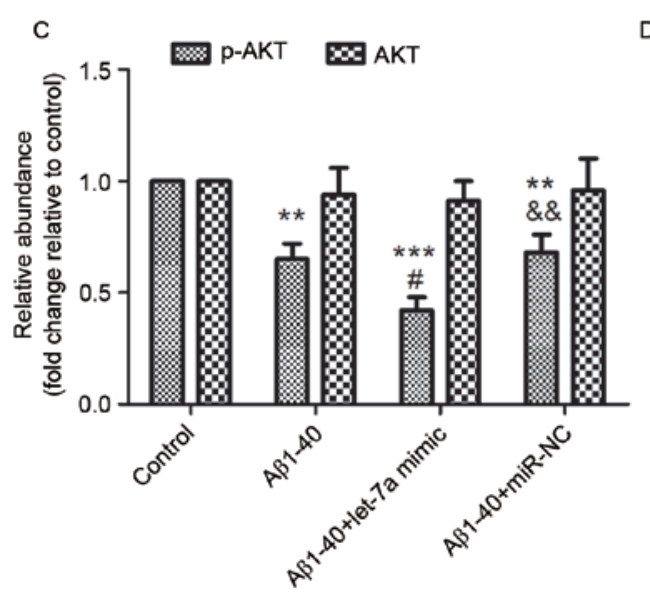

D

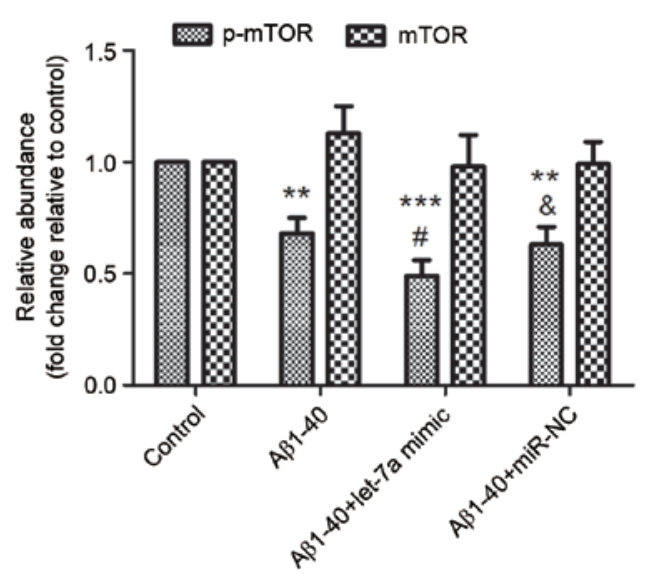

Figure 6. Effect of let-7a overexpression on the PI3K/Akt/mTOR signaling pathway. (A) The protein levels of PI3K, p-Akt, Akt, p-mTOR and mTOR were detected by western blot analysis. $\beta$-actin was used as a loading control. (B-D) Densitometric analysis of each protein band. Data are presented as the mean \pm standard deviation $(\mathrm{n}=3) .{ }^{* *} \mathrm{P}<0.01,{ }^{* * * *} \mathrm{P}<0.001$ vs. control group; ${ }^{\sharp \mathrm{P}}<0.05$ vs. $\mathrm{A} \beta 1-40$ group; ${ }^{\&} \mathrm{P}<0.05,{ }^{\& \&} \mathrm{P}<0.01$ vs. $\mathrm{A} \beta 1-40+$ let-7a mimic group. $\mathrm{A} \beta$, $\beta$-amyloid; miR-NC, negative control microRNA; PI3K, phosphoinositide-3-kinase; p-, phosphorylated; mTOR, mammalian target of rapamycin.

leading view is that in the early stage of $\mathrm{AD}$, autophagy is beneficial in clearing $\mathrm{A} \beta$ accumulation. With the progress of $\mathrm{AD}$, autophagic-lysosomal pathway dysfunction results in the accumulation of immature AVs, which promotes A $\beta$ production (32). LC3 is recognized as a specific marker for autophagy. LC3-I and LC3-II are two key subtypes of LC3 and the conversion of LC3-I to LC3-II indicates autophagy activation (33). Beclin-1 is an autophagy regulatory protein and is able to control the onset of autophagy (34). The level of beclin-1 has previously been demonstrated to be increased in NG108-15 neural cells of $A \beta 25$-35-treated mice (35). The present data indicated that autophagy was activated by $\mathrm{A} \beta 1-40$ treatment via promoting the conversion of LC3-I to LC3-II and increasing the level of beclin-1, which was enhanced by overexpression of let-7a. Atg-5 and Atg-7 serve a function in the membrane-expansion process in autophagosome formation, and overexpression of Atg-5 and Atg-7 may facilitate the activation of autophagy (36). The present results were consistent with this and indicated that let-7a overexpression further promoted the increased levels of Atg-5 and Atg-7 induced by A $\beta 1-40$. However, the above results only reflected the upstream processes of autophagy. The level of p62 protein is inversely proportional to the downstream processes of autophagy activation. An increased level of p62 indicates suppression of the autophagy-lysosomal pathway, which leads to impaired autophagy $(37,38)$. If autophagic-lysosomal dysfunction occurs, a large number of AVs may be accumulated, contributing to the course of AD (39). In the present study, the level of p62 was increased in A 31 -40-treated PC12 cells compared with the control, and was further upregulated by let-7a overexpression, indicating that let-7a overexpression aggravated the autophagic-lysosomal dysfunction. Furthermore, inhibition of autophagy by 3-MA significantly suppressed the apoptosis induced by let-7a overexpression. The above results suggested that autophagy regulation was associated with A $\beta 1-40$-induced neurotoxicity in vitro and overexpression of let-7a exacerbated neurotoxicity via inducing impaired autophagy.

Autophagy is regulated by various signaling pathways. The mTOR kinase pathway is a key regulator of autophagy, which is controlled by its upstream PI3K/Akt pathway (40). mTOR has a negative feedback effect on autophagy and inhibition of the PI3K/Akt/mTOR pathway can activate autophagy $(41,42)$. In the present study, it was demonstrated that the levels of PI3K, p-Akt and p-mTOR were downregulated by A $\beta 1-40$ treatment compared with the control. Furthermore, let-7a 
A

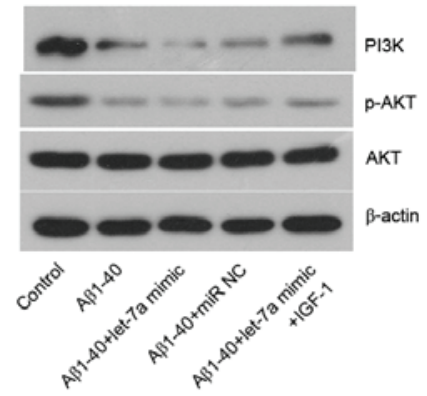

B

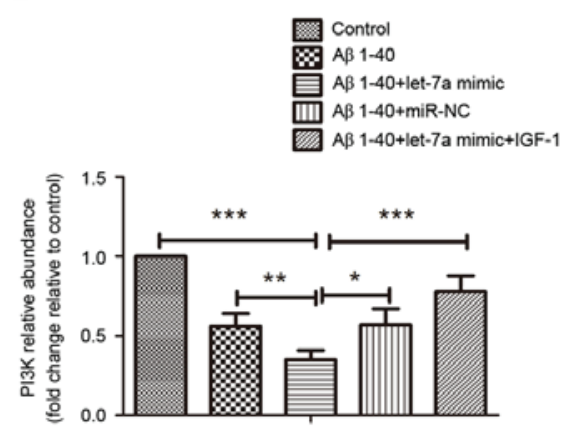

C

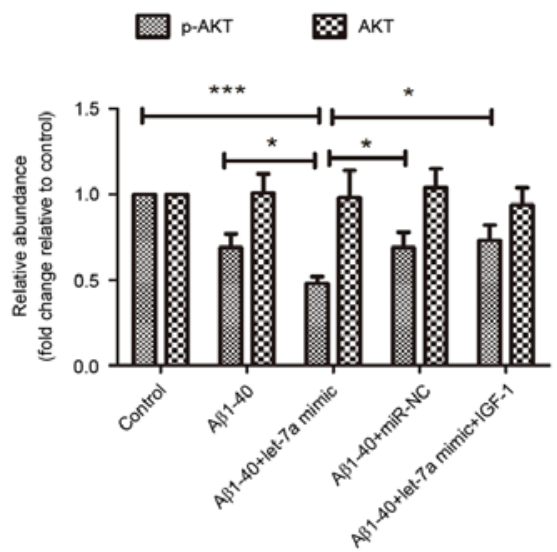

D

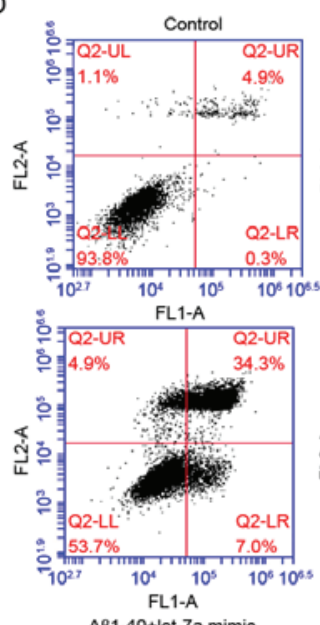

A $\beta 1-40+$ let-7a mimic
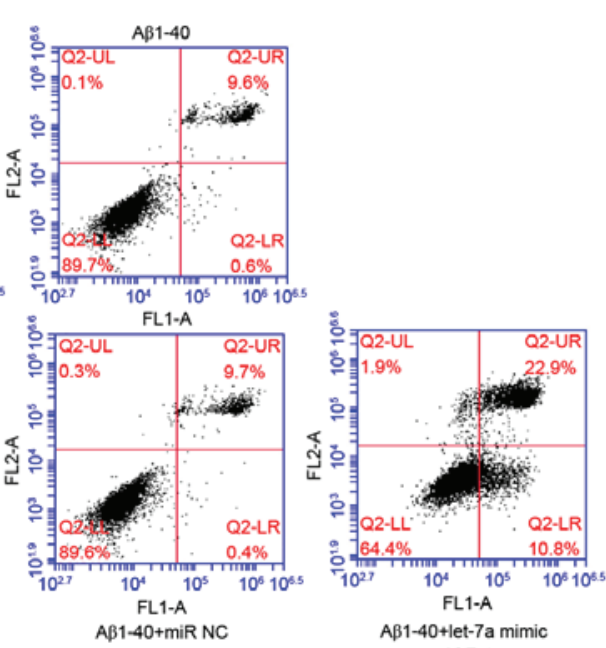

+IGF-1

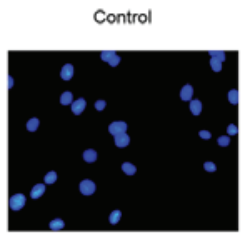

G

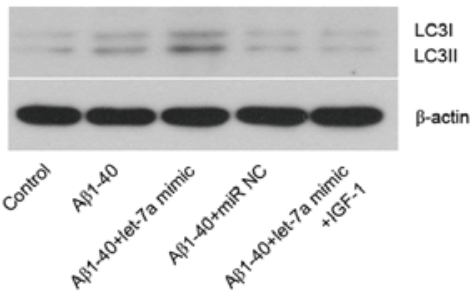

E

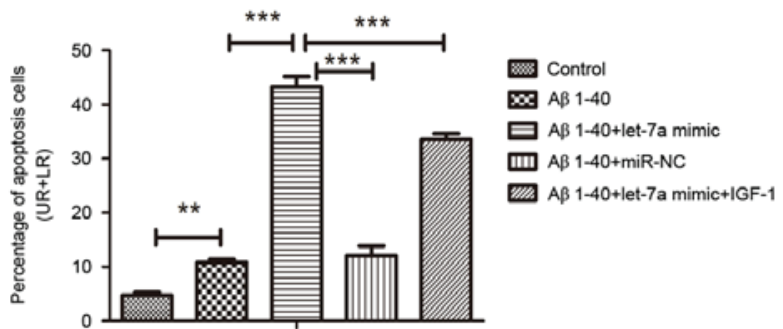

A $1-40+$ miR NC

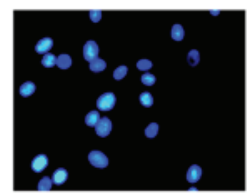

$\mathrm{H}$

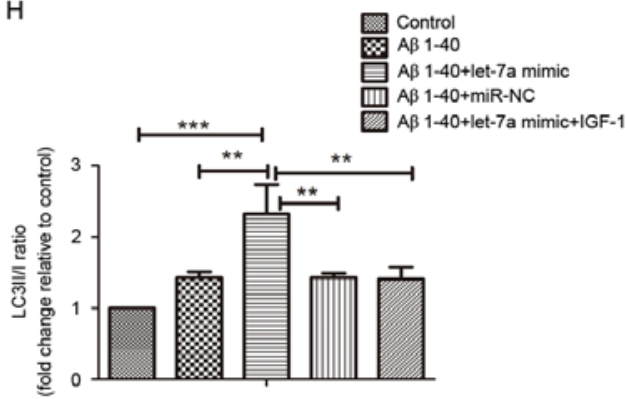

Figure 7. Effect of PI3K/Akt pathway activation on apoptosis and autophagy. (A) The protein levels of PI3K, p-Akt and Akt in PC12 cells were detected by western blot analysis. $\beta$-actin was used as a loading control. (B and C) Densitometric analysis of each protein band. (D) The apoptosis rate in PC12 cells was determined by flow cytometry. (E) The percentages of apoptosis cells in the UR \& LR quadrants are presented in the column charts. (F) Representative images of the morphological changes of nuclei in PC12 cells stained by Hoechst 33342 (magnification, x400). (G) Protein levels of LC3 I and LC3 II were detected by western blot analysis. $\beta$-actin was used as a loading control. $(\mathrm{H})$ Densitometric analysis of each protein band. Data are presented as the mean \pm standard deviation $(\mathrm{n}=3) .{ }^{*} \mathrm{P}<0.05,{ }^{* *} \mathrm{P}<0.01,{ }^{* * *} \mathrm{P}<0.001$ as indicated. UR, upper right; LR, lower right; A $\beta$, $\beta$-amyloid; miR-NC, negative control microRNA; LC3, microtubule-associated protein 1A/1B-light chain 3; PI3K, phosphoinositide-3-kinase; IGF-1, insulin-like growth factor 1.

overexpression was able to further decrease the expression levels of these proteins compared with the A $\beta 1-40$ treatment group. Activation of the PI3K/Akt pathway by IGF-1 also inhibited the autophagy and apoptosis induced by let-7a overexpression in A $31-40$-treated PC12 cells. The above results suggested that let-7a overexpression promotes impaired autophagy induced by $A \beta 1-40$ via inhibition of the PI3K/Akt/mTOR signaling pathway in vitro.

In conclusion, the present study demonstrated that $\mathrm{A} \beta 1-40$ could induce neurotoxicity in PC12 and SK-N-SH cells. 
Furthermore, let-7a overexpression was indicated to increase the neurotoxic effects of $A \beta 1-40$ by inducing impaired autophagy. In addition, the PI3K/Akt/mTOR signaling pathway was demonstrated to be associated with the autophagy regulation of let-7a. Although the related mechanisms require further investigation, the present results suggest that let-7a may serve as a promising tool for the study of AD.

\section{References}

1. Choi SH, Kim YH, Hebisch M, Sliwinski C, Lee S, D'Avanzo C, Chen H, Hooli B, Asselin C, Muffat J, et al: A three-dimensional human neural cell culture model of Alzheimer's disease. Nature 515: 274-278, 2014.

2. Hebert LE, Weuve J, Scherr PA and Evans DA: Alzheimer disease in the United States (2010-2050) estimated using the 2010 census. Neurology 80: 1778-1783, 2013.

3. Keogh-Brown MR, Jensen HT, Arrighi HM and Smith RD: The impact of Alzheimer's disease on the Chinese economy. EBioMedicine 4: 184-190, 2015.

4. Saiz-Sanchez D, De la Rosa-Prieto C, Ubeda-Banon I and Martinez-Marcos A: Interneurons, tau and amyloid- $\beta$ in the piriform cortex in Alzheimer's disease. Brain Struct Funct 220: 2011-2025, 2015

5. Pamphlett R and Kum Jew S: Different populations of human locus ceruleus neurons contain heavy metals or hyperphosphorylated tau: Implications for amyloid- $\beta$ and tau pathology in Alzheimer's disease. J Alzheimers Dis 45: 437-447, 2015.

6. Tung YT, Wang BJ, Hu MK, Hsu WM, Lee H, Huang WP and Liao YF: Autophagy: A double-edged sword in Alzheimer's disease. J Biosci 37: 157-165, 2012.

7. Dai R, Zhang S, Duan W, Wei R, Chen H, Cai W, Yang L and Wang Q: Enhanced autophagy contributes to protective effects of GM1 ganglioside against A $\beta 1$-42-induced neurotoxicity and cognitive deficits. Neurochem Res: May 12, 2017 (Epub ahead of print).

8. Singh AK, Bissoyi A, Kashyap MP, Patra PK and Rizvi SI Autophagy activation alleviates amyloid- $\beta$-induced oxidative stress, apoptosis and neurotoxicity in human neuroblastoma SH-SY5Y cells. Neurotox Res: May 8, 2017 (Epub ahead of print).

9. Fan Y, Wang N, Rocchi A, Zhang W, Vassar R, Zhou Y and He C: Identification of natural products with neuronal and metabolic benefits through autophagy induction. Autophagy 13: 41-56, 2017.

10. Bordi M, Berg MJ, Mohan PS, Peterhoff CM, Alldred MJ, Che S, Ginsberg SD and Nixon RA: Autophagy flux in CA1 neurons of Alzheimer hippocampus: Increased induction overburdens failing lysosomes to propel neuritic dystrophy. Autophagy 12: 2467-2483, 2016.

11. Yu WH, Kumar A, Peterhoff C, Shapiro Kulnane L, Uchiyama Y, Lamb BT, Cuervo AM and Nixon RA: Autophagic vacuoles are enriched in amyloid precursor protein-secretase activities: Implications for beta-amyloid peptide over-production and localization in Alzheimer's disease. Int J Biochem Cell Biol 36: 2531-2540, 2004.

12. Nixon RA, Wegiel J, Kumar A, Yu WH, Peterhoff C, Cataldo A and Cuervo AM: Extensive involvement of autophagy in Alzheimer disease: An immuno-electron microscopy study. J Neuropathol Exp Neurol 64: 113-122, 2005.

13. Rubinsztein DC, DiFiglia M, Heintz N, Nixon RA, Qin ZH, Ravikumar B, Stefanis L and Tolkovsky A: Autophagy and its possible roles in nervous system diseases, damage and repair. Autophagy 1: 11-22, 2005.

14. Yang DS, Stavrides P, Mohan PS, Kaushik S, Kumar A, Ohno M, Schmidt SD, Wesson DW, Bandyopadhyay U, Jiang Y, et al: Therapeutic effects of remediating autophagy failure in a mouse model of Alzheimer disease by enhancing lysosomal proteolysis. Autophagy 7: 788-789, 2011

15. Cho SJ, Yun SM, Jo C, Lee DH, Choi KJ, Song JC, Park SI, Kim YJ and Koh YH: SUMO1 promotes A $\beta$ production via the modulation of autophagy. Autophagy 11: 100-112, 2015.

16. Lee H, Han S, Kwon CS and Lee D: Biogenesis and regulation of the let-7 miRNAs and their functional implications. Protein Cell 7: 100-113, 2016.

17. Thornton JE and Gregory RI: How does Lin28 let-7 control development and disease? Trends Cell Biol 22: 474-482, 2012 .
18. Dubinsky AN, Dastidar SG, Hsu CL, Zahra R, Djakovic SN Duarte S, Esau CC, Spencer B, Ashe TD, Fischer KM, et al: Let-7 coordinately suppresses components of the amino acid sensing pathway to repress $\mathrm{mTORC1}$ and induce autophagy. Cell Metab 20: 626-638, 2014.

19. Liu QY, Chang MN, Lei JX, Koukiekolo R, Smith B, Zhang D and Ghribi O: Identification of microRNAs involved in Alzheimer's progression using a rabbit model of the disease. Am J Neurodegener Dis 3: 33-44, 2014.

20. Kumar P, Dezso Z, MacKenzie C, Oestreicher J, Agoulnik S, Byrne M, Bernier F, Yanagimachi M, Aoshima K and Oda Y: Circulating miRNA biomarkers for Alzheimer's disease. PLoS One 8: e69807, 2013

21. Livak KJ and Schmittgen TD: Analysis of relative gene expression data using real-time quantitative PCR and the 2(-Delta Delta C(T)) method. Methods 25: 402-408, 2001.

22. Li TT, Zhu D, Mou T, Guo Z, Pu JL, Chen QS, Wei XF and Wu ZJ: IL-37 induces autophagy in hepatocellular carcinoma cells by inhibiting the PI3K/AKT/mTOR pathway. Mol Immunol 87: 132-140, 2017.

23. Muñoz FJ and Inestrosa NC: Neurotoxicity of acetylcholinesterase amyloid beta-peptide aggregates is dependent on the type of Abeta peptide and the AChE concentration present in the complexes. FEBS Lett 450: 205-209, 1999.

24. Tomiyama T, Shoji A, Kataoka K, Suwa Y, Asano S, Kaneko H and Endo N: Inhibition of amyloid beta protein aggregation and neurotoxicity by rifampicin. Its possible function as a hydroxyl radical scavenger. J Biol Chem 271: 6839-6844, 1996.

25. Takahashi RH, Nagao T and Gouras GK: Plaque formation and the intraneuronal accumulation of $\beta$-amyloid in Alzheimer's disease. Pathol Int 67: 185-193, 2017.

26. Kong Y, Li K, Fu T, Wan C, Zhang D, Song H, Zhang Y, Liu N, Gan $Z$ and Yuan L: Quercetin ameliorates $A \beta$ toxicity in Drosophila AD model by modulating cell cycle-related protein expression. Oncotarget 7: 67716-67731,2016.

27. Rajmohan R and Reddy PH: Amyloid-beta and phosphorylated tau accumulations cause abnormalities at synapses of Alzheimer's disease neurons. J Alzheimers Dis 57: 975-999, 2017.

28. Gupta VK, Chitranshi N, Gupta VB, Golzan M, Dheer Y, Wall RV, Georgevsky D, King AE, Vickers JC, Chung R and Graham S: Amyloid beta accumulation and inner retinal degenerative changes in Alzheimer's disease transgenic mouse. Neurosci Lett 623: 52-56, 2016.

29. Nixon RA: Autophagy, amyloidogenesis and Alzheimer disease. J Cell Sci 120: 4081-4091, 2007.

30. Lipinski MM, Zheng B, Lu T, Yan Z, Py BF, Ng A, Xavier RJ, Li C, Yankner BA, Scherzer CR and Yuan J: Genome-wide analysis reveals mechanisms modulating autophagy in normal brain aging and in Alzheimer's disease. Proc Natl Acad Sci USA 107: 14164-14169, 2010

31. Spilman P, Podlutskaya N, Hart MJ, Debnath J, Gorostiza O, Bredesen D, Richardson A, Strong R and Galvan V: Inhibition of mTOR by rapamycin abolishes cognitive deficits and reduces amyloid-beta levels in a mouse model of Alzheimer's disease. PLoS One 5: e9979, 2010.

32. Kiriyama Y and Nochi H: The function of autophagy in neurodegenerative diseases. Int J Mol Sci 16: 26797-26812, 2015.

33. Kabeya Y, Mizushima N, Ueno T, Yamamoto A, Kirisako T, Noda T, Kominami E, Ohsumi Y and Yoshimori T: LC3, a mammalian homologue of yeast Apg8p, is localized in autophagosome membranes after processing. EMBO J 19: 5720-5728, 2000.

34. Salminen A, Kaarniranta K, Kauppinen A, Ojala J, Haapasalo A, Soininen $\mathrm{H}$ and Hiltunen $\mathrm{M}$ : Impaired autophagy and APP processing in Alzheimer's disease: The potential role of Beclin 1 interactome. Prog Neurobiol 106-107: 33-54, 2013.

35. Du B, Zhang Z and Li N: Madecassoside prevents $\mathrm{A} \beta(25-35)$-induced inflammatory responses and autophagy in neuronal cells through the class III PI3K/Beclin-1/Bcl-2 pathway. Int Immunopharmacol 20: 221-228, 2014.

36. Song F, Kou R, Zou C, Gao Y, Zeng T and Xie K: Involvement of autophagy in tri-ortho-cresyl phosphate- induced delayed neuropathy in hens. Neurochem Int 64: 1-8, 2014.

37. Komatsu M, Waguri S, Koike M, Sou YS, Ueno T, Hara T, Mizushima N, Iwata J, Ezaki J, Murata S, et al: Homeostatic levels of p62 control cytoplasmic inclusion body formation in autophagy-deficient mice. Cell 131: 1149-1163, 2007.

38. Waguri S and Komatsu M: Biochemical and morphological detection of inclusion bodies in autophagy-deficient mice. Methods Enzymol 453: 181-196, 2009. 
39. Ihara Y, Morishima-Kawashima M and Nixon R: The ubiquitin-proteasome system and the autophagic-lysosomal system in Alzheimer disease. Cold Spring Harb Perspect Med 2: pii: a006361, 2012.

40. Petiot A, Ogier-Denis E, Blommaart EF, Meijer AJ and Codogno P: Distinct classes of phosphatidylinositol 3'-kinases are involved in signaling pathways that control macroautophagy in HT-29 cells. J Biol Chem 275: 992-998, 2000.
41. Wang P, Guo QS, Wang ZW and Qian HX: HBx induces HepG-2 cells autophagy through PI3K/Akt-mTOR pathway. Mol Cell Biochem 372: 161-168, 2013.

42. Liu J, Hu XJ, Jin B, Qu XJ, Hou KZ and Liu YP: $\beta$-Elemene induces apoptosis as well as protective autophagy in human non-small-cell lung cancer A549 cells. J Pharm Pharmacol 64: 146-153, 2012. 